\title{
Central lead administration inhibits water intake and sodium appetite in rats
}

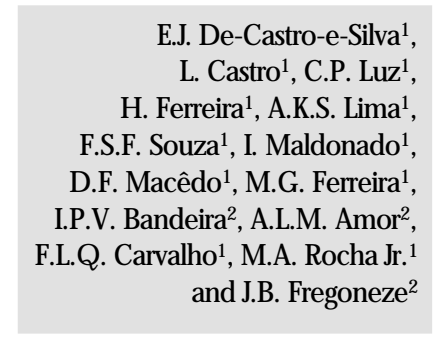

E.J. De-Castro-e-Silva',

L. Castro ${ }^{1}$, C.P. Luz ${ }^{1}$

D.F. Macêdoㅁ, M.G. Ferreira' ${ }^{1}$

I.P.V. Bandeira², A.L.M. Amor'²,

and J.B. Fregoneze

\section{Correspondence}

E.J. De-Castro-e-Silva

Departamento de Fisiologia

Instituto de Ciências da Saúde

Universidade Federal da Bahia

40110-100 Salvador, BA

Brasil

Fax: +55-71-337-0195

E-mail: emilio@ svn.com.br

Research supported by CN Pq (Nos. 300772/86-2 and 301099/92-8) and by the Bahia State Research Support Financial Agency (CADCT).

Received March 24, 1999

Accepted August 11, 1999

\author{
${ }^{1}$ Departamento de Fisiologia, Instituto de Ciências da Saúde, and \\ ${ }^{2}$ Departamento de Zoologia, Instituto de Biologia, \\ Universidade Federal da Bahia, Salvador, BA, Brasil
}

\section{Abstract}

We have demonstrated that acute third ventricle injections of lead acetate $(\mathrm{PbAc})$ exert a powerful antidipsogenic effect and induce a significant increase in renal sodium excretion. In the present study we confirm the antidipsogenic effect of lead and demonstrate that central administration of this metal, in minute amounts, significantly reduces salt intake both during dehydration and after central angiotensinergic stimulation. Adult male Wistar rats had the third ventricle cannulated seven days before the experiments. During this period they had free access to distilled water and hypertonic saline solution (1.5\%). After a 24-h period of fluid deprivation, experimental animals received third ventricle injections of $\mathrm{PbAc}(0.3, \mathrm{~N}=8$ and $3.0 \mathrm{nmol} / \mathrm{rat}, \mathrm{N}=14)$ while controls received sodium acetate $(\mathrm{NaAc} ; 3.0 \mathrm{nmol} / \mathrm{rat}, \mathrm{N}=10)$. Rats treated with $\mathrm{PbAc}$ at the highest dose showed a significant reduction $(\mathrm{P}<0.05)$ both in water and hypertonic saline intake when compared to controls. When the effect of lead administration on angiotensin II-induced water and salt intake was studied, normohydrated animals received third ventricle injections of angiotensin II (9.6 $\mathrm{nmol} / \mathrm{rat}$ ) after pretreatment with $3.0 \mathrm{nmol} / \mathrm{rat}$ of $\mathrm{PbAc}$ (experimental group, $\mathrm{N}=10$ ) or $\mathrm{NaAc}$ (controls, $\mathrm{N}=8$ ). The group pretreated with $\mathrm{PbAc}$ presented a significant reduction $(\mathrm{P}<0.05)$ in both water and salt intake compared to controls. Thus, this study confirms the antidipsogenic effect of central lead injections and demonstrates that the presence of lead in the brain exerts a significant inhibition of sodium appetite.

Lead, a non-physiological metal widely distributed in the environment, is still considered an important developmental neurotoxicant that induces cognitive deficits in humans even at low blood levels such as 10 $\mu \mathrm{g} / \mathrm{dl}(1,2)$. Under experimental conditions, lead alters complex behaviors such as rever- sal learning, drug discrimination, spatial learning and stress behaviors in rats (3). Less is certain about the effects of lead on the adult mammalian brain. However, learning and memory impairments are reported in response to occupational lead exposure (4). There is a growing need for studies of the 
effect of lead on animal behavior, as commented elsewhere (5).

We have demonstrated that acute third ventricle injections of lead in minute amounts induce a significant antidipsogenic effect on dehydrated rats, as well as in those whose drinking was induced by central angiotensinergic, cholinergic and $\beta$-adrenergic stimulation $(6,7)$. This thirst-inhibiting effect of central lead administration may be, at least in part, opioid-dependent, as we have also shown (8). Recently, we have demonstrated that central injection of lead, in the same amounts used to inhibit water intake, causes a significant increase in renal sodium and potassium excretion (9). Thus, central lead administration disturbs brain mechanisms related to several aspects of fluid and electrolyte control.

In the present study we investigate in adult rats the effects of third ventricle injections of lead on sodium appetite, a further variable related to the homeostatic control of body fluids and electrolytes that is strictly and continuously controlled by the brain.

We used adult male Wistar rats kept under controlled light (lights on from 6:00 to $20: 00 \mathrm{~h})$ and temperature $\left(26 \pm 2^{\circ} \mathrm{C}\right)$ conditions. The third ventricle of the animals was cannulated as described elsewhere (10) seven days before the experimental sessions. Briefly, the animals were anesthetized with sodium pentobarbital $(40 \mathrm{mg} / \mathrm{kg}$, intraperitoneally). After exposure of the skull, two screws were embedded into the bone to allow the anchorage of the cannula with dental acrylic. The following coordinates were used: anteroposterior $=0.5 \mathrm{~mm}$ behind the bregma, lateral $=$ just on the midline, and vertical $=$ $8.5 \mathrm{~mm}$ below the skull. A mandril (28 gauge) was inserted into the cannula to avoid obstruction. After the experiments, the animals were sacrificed and received third ventricle injections of Evans blue ( $2 \mu 1,5 \%)$; the brains were then removed and the position of the cannula was verified. Only animals whose cannulas were inserted exactly into the third ventricle were considered.

The following drugs were used: angiotensin II, lead acetate $(\mathrm{PbAc})$ and sodium acetate $(\mathrm{NaAc})$ obtained from Sigma Chemical Co., St. Louis, MO, USA. All drugs were dissolved in isotonic saline solution and injected into the third ventricle with a $10-\mu 1$ Hamilton syringe connected to a MizzySlide-Pak needle through polyethylene tubing. The volume injected into the third ventricle was $2 \mu \mathrm{l}$ and the injections were made over a period of $60 \mathrm{~s}$. Naive animals were used in all experiments (always performed between 8:00 and 11:00 a.m.).

During the days between stereotaxic cannulation of the third ventricle and the experimental session all animals had free access to two bottles containing distilled water or hypertonic saline solution (1.5\%). To study the effect of central injection of $\mathrm{PbAc}$ on sodium appetite in dehydrated animals, both bottles were removed from the cages $24 \mathrm{~h}$ before the experiments and were reintroduced into the cages immediately after PbAc injection, when the intake of both fluids began to be recorded. To investigate the effect of PbAc on sodium appetite in normohydrated animals receiving angiotensin II, this peptide was injected into the third ventricle $30 \mathrm{~min}$ after $\mathrm{PbAc}$ injections. The intake of both fluids began to be recorded immediately after angiotensin II injections. In both cases fluid intake was monitored for $120 \mathrm{~min}$.

$\mathrm{NaAc}$ injection was used as control for groups receiving $\mathrm{PbAc}$. We have shown that $\mathrm{NaAc}$ injection into the third ventricle does not modify water or hypertonic saline solution intake when compared to animals receiving central injections of isotonic saline (6).

Data were analyzed statistically by repeated measures analysis of variance (ANOVA) followed by the Student-Newman-Keuls test using a computer software (SigmaStat for Windows, Jandel Scientific, San Rafael, CA, USA). Differences were considered significant when $\mathrm{P}<0.01$. The 
cumulative intake of water or hypertonic saline solution is presented as $\mathrm{ml} / 100 \mathrm{~g}$ body weight (mean $\pm \mathrm{SEM}$ ).

Figure 1 shows the effect of PbAc injections into the third ventricle on water and hypertonic saline intake by dehydrated animals. Panel A shows that, as expected, dehydrated control animals receiving $\mathrm{NaAc}$ exhibited a high water intake. At the lowest dose employed ( $0.3 \mathrm{nmol} / \mathrm{rat}) \mathrm{PbAc}$ was ineffective. At the highest dose employed (3.0 $\mathrm{nmol} / \mathrm{rat}$ ) PbAc administration induced a significant reduction in water intake after 45 min that lasted for the entire duration of the experiment. The percent inhibition from 45 min until the end of the experiment continued to be about $35 \%$, as seen in panel B. Panel $\mathrm{C}$ shows that even at the lowest dose employed $(0.3 \mathrm{nmol} / \mathrm{rat}) \mathrm{PbAc}$ generated a partial but significant blunting of salt intake after 90 to $120 \mathrm{~min}$. At the highest dose employed ( $3.0 \mathrm{nmol} / \mathrm{rat})$ a significant blockade in hypertonic saline intake was evident after $10 \mathrm{~min}$, persisting until the end of the experiment. The magnitude of this blockade was very high, corresponding to about $85 \%$ inhibition, as seen in panel D. Comparing panels $\mathrm{B}$ and $\mathrm{D}$ in Figure 1, it is easy to observe that $\mathrm{PbAc}$ more potently inhibited hypertonic saline intake than water intake.

Figure 2 shows the effect of $\mathrm{PbAc}$ on water and hypertonic saline intake by normohydrated animals receiving angiotensin II, pretreated with $\mathrm{PbAc}(3.0 \mathrm{nmol} / \mathrm{rat})$ or $\mathrm{NaAc}(3.0 \mathrm{nmol} / \mathrm{rat})$. As seen in panel A, control animals receiving angiotensin II (9.6 $\mathrm{nmol} / \mathrm{rat}$ ) but pretreated with $\mathrm{NaAc}$ exhibited a high water intake, as expected. Pretreatment with $\mathrm{PbAc}$ induced a significant blockade of water intake during the entire duration of the experiment. Normohydrated animals receiving $\mathrm{NaAc}$ presented a very low water intake as usual. The high percentage of water intake inhibition is depicted in panel B. Control animals receiving angiotensin II and pretreated with $\mathrm{NaAc}$ showed a high hypertonic saline intake, as seen in panel C. Pretreatment with PbAc significantly blocked this natriorexigenic response. As expected, normohydrated animals receiving NaAc alone displayed a very low intake of hypertonic saline. The percentage of inhibition of hypertonic saline intake is illustrated in panel D.

The present study extends observations from our laboratory on the acute effects of heavy metals on central regulation of fluid and electrolytes in rats. We have previously shown that lead injections into the third ventricle induce a significant antidipsogenic ef-
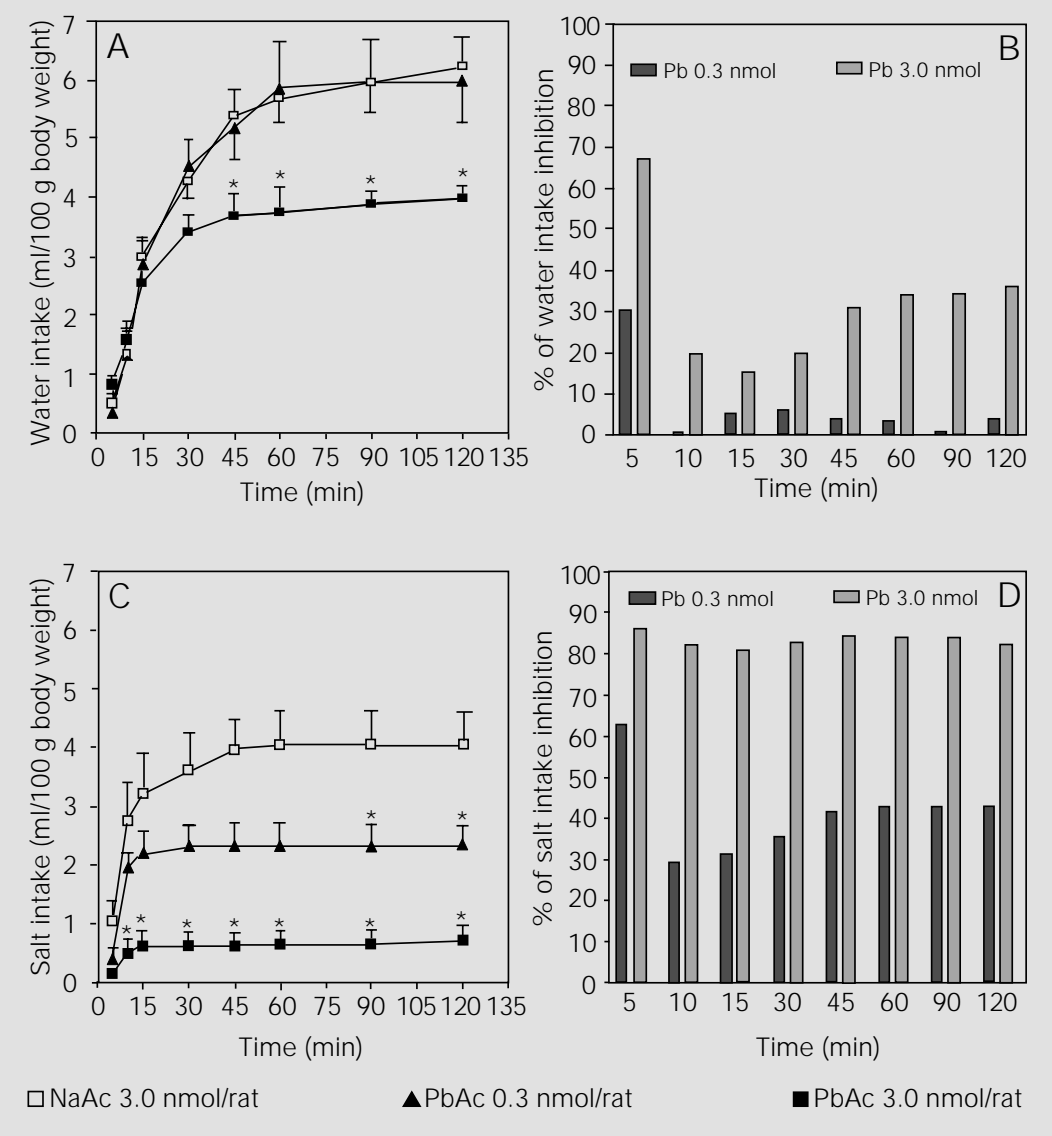

Figure 1 - Cumulative water and salt intake ( $\mathrm{ml} / 100 \mathrm{~g}$ body weight) by rats after a $24-\mathrm{h}$ period of water deprivation. Absolute values of water intake are presented in panel $A$. The percentage of lead-induced water intake inhibition (as compared to NaAc-treated rats) is shown in panel $\mathrm{B}$. Absolute values of hypertonic saline intake are presented in panel $\mathrm{C}$. The percentage of lead-induced hypertonic saline intake inhibition (as compared to NaAc-treated rats) is shown in panel $\mathrm{D}$. Absolute values are presented as means $\pm \mathrm{SEM}$. $* \mathrm{P}<0.05$ compared to the control group receiving NaAc (ANOVA followed by Student-NewmanKeuls test). Open squares $(\mathrm{N}=10)$, NaAc $3.0 \mathrm{nmol} / \mathrm{rat}$; triangles $(\mathrm{N}=8), \mathrm{PbAc} 0.3 \mathrm{nmol} / \mathrm{rat}$, and closed squares $(\mathrm{N}=14), \mathrm{PbAc} 3.0 \mathrm{nmol} / \mathrm{rat}$. 
fect in several physiological and pharmacological situations $(6,7)$, an effect due, at least partially, to a stimulation of central opioid pathways (8). More recently, we have demonstrated that acute intracerebroventricular injections of lead induce a powerful natriuretic and kaliuretic effect (9). Here, we confirm that central lead injections diminish water intake after dehydration and central angiotensinergic stimulation. More importantly, we show that third ventricle injections of lead significantly reduce sodium appetite.
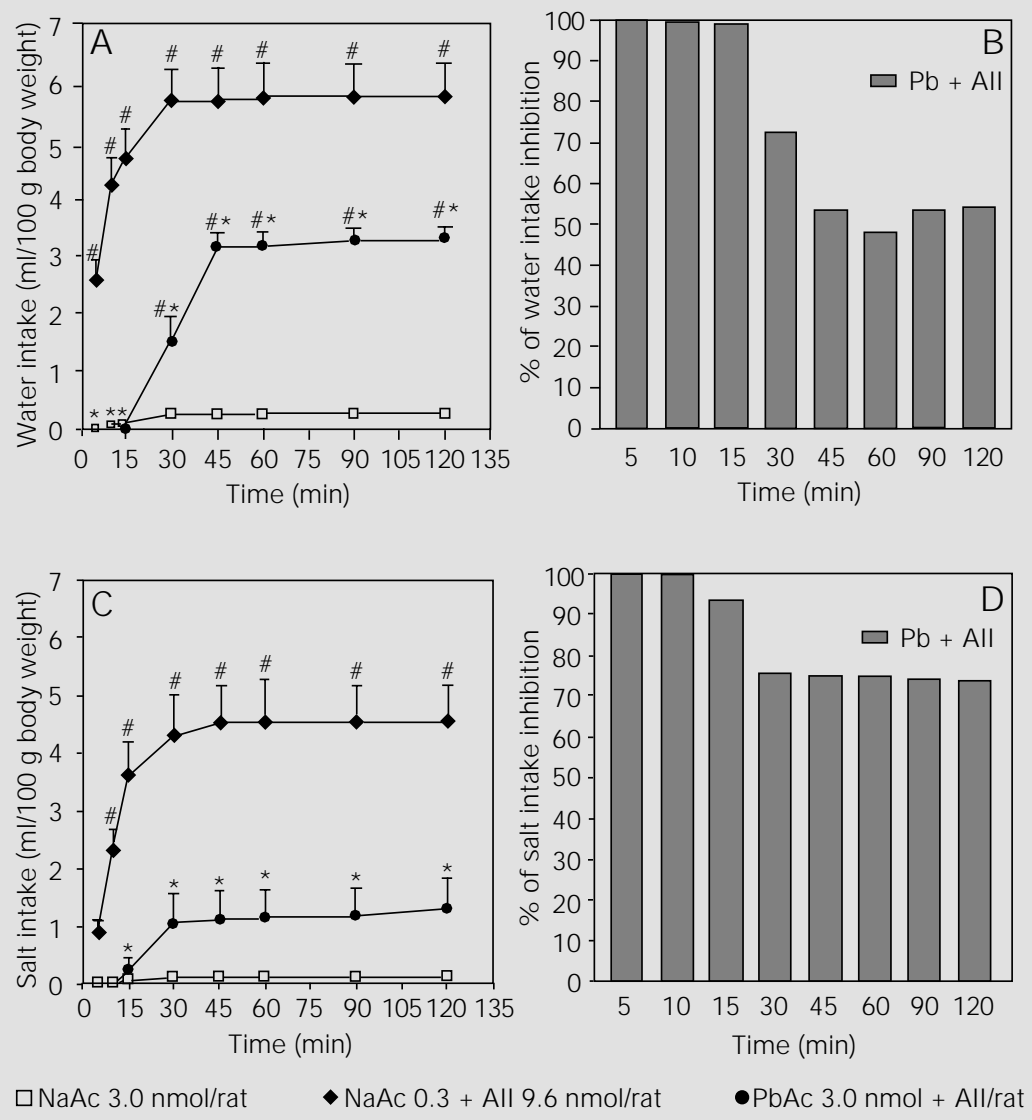

Figure 2 - Cumulative water and salt intake $(\mathrm{ml} / 100 \mathrm{~g}$ body weight) by rats after third ventricle injections of angiotensin II (All; $9.6 \mathrm{nmol} / \mathrm{rat}$ ). Absolute values of water intake are presented in panel $A$. The percentage of lead-induced water intake inhibition (as compared to NaAc-treated rats) is shown in panel B. Absolute values of hypertonic saline intake are presented in panel $\mathrm{C}$. The percentage of lead-induced hypertonic saline intake inhibition (as compared to NaAc-treated rats) is shown in panel D. Absolute values are presented as means \pm SEM. $* \mathrm{P}<0.05$ for the group receiving $\mathrm{NaAc}+$ All compared to the group receiving $\mathrm{PbAc}+$ All (ANOVA followed by Student-Newman-Keuls test). ${ }^{\#}<0.05$ for the group receiving NaAc alone compared to both other groups. Squares $(N=9), N a A c 3.0 \mathrm{nmol} / \mathrm{rat}$; lozenges $(\mathrm{N}=8), \mathrm{NaAc}+\mathrm{All}$, and circles $(\mathrm{N}=10), \mathrm{PbAc} 3.0 \mathrm{nmol}+\mathrm{All} / \mathrm{rat}$.
No biological function has been demonstrated for lead. Contamination by lead may cause an endless sequence of pathological manifestations extensively reviewed elsewhere (4). The central nervous system may be especially sensitive to lead poisoning. Both the developing and the adult brain are especially prone to functional disturbances even when blood concentrations of the metal are very low. It is well established that lead alters the functional integrity of the bloodbrain barrier, facilitating its entry into the brain (11). Once in the brain, lead presents a homogeneous distribution, being localized both in neurons and glia. By interfering with many biochemical processes, lead may alter a myriad of cellular events that potentially affect brain function. Neurotransmitter kinetics derangement, voltage-dependent calcium channel blockade and alterations in calcium function by spurious binding with calcium-binding proteins are the most common mechanisms by which lead distorts the cellular machinery (12).

The brain controls many aspects related to the homeostatic processes necessary to keep body fluid and electrolyte variables within the proper narrow limits. Fluctuations in these variables make the brain trigger regulatory mechanisms that include thirst, renal water and electrolyte excretion and sodium appetite. The central regions localized in the vicinity of the third ventricle are especially involved in these homeostatic procedures, the most important being the hypothalamus, the subfornical organ, the organum vasculosum lamina terminalis and the anteroventral third ventricle region (AV3V) (13). In this study lead was injected into the third ventricle, a route that provides fast access to these structures.

In the present study acute third ventricle injections of lead inhibited water intake after both dehydration and angiotensinergic stimulation. This effect had already been demonstrated in our laboratory, as mentioned above. We show here that sodium appetite, an im- 
portant contributory mechanism in the process of body fluid and electrolyte control, is also affected by central lead administration. Forebrain circumventricular structures play a facilitatory role in thirst and sodium appetite, in contrast to those located in the hindbrain that exert an inhibitory modulation of these behaviors. As we injected lead into the third ventricle, it is reasonable to suggest that, in this case, central lead disrupts both the thirst and salt intake triggering capacities of these forebrain regions. It is also clear that the structures involved in thirst generation and sodium intake induction are differentially affected by lead. Indeed, lead injections block salt intake much more easily than water intake.

Our experimental protocol was specifically designed to evaluate salt-intake behavior. We used hypertonic saline solution $(1.5 \%)$ that is normally aversive to rats. Thus, ingestion of this solution means a salt-replenishing behavior. In other words, when rats drink hypertonic saline solution they are obeying a central salt-seeking command and this behavior does not represent a natriophilic hedonic behavior.

We have previously shown that central lead increases renal sodium excretion. An increase in sodium excretion coupled with a reduction in salt intake is a situation that favors efficient correction of hypernatremia and/or hyperosmolarity. Thus, it is reasonable to suggest that central lead injections may activate areas that normally trigger com- pensatory mechanisms in response to these two conditions.

Central angiotensin II exerts powerful dipsogenic and natriorexigenic effects and central angiotensinergic activity increases during dehydration (14). Central lead injections inhibited salt intake after both dehydration and central angiotensinergic stimulation. Thus, it seems rational to suggest that the inhibitory effects of lead on salt intake rely on structures or components localized "downstream" of angiotensinergic components.

It is necessary to stress that the effects of lead demonstrated here were obtained with concentrations far below those normally present in the central nervous system of intoxicated humans and laboratory animals, which range from 4.9 to $7 \mu \mathrm{g} / \mathrm{g}$ of tissue (15).

Taken together, the present data and those previously reported by our laboratory clearly show that lead in the brain may disturb the homeostatic control of body fluids in several ways. Indeed, it inhibits thirst, increases renal sodium excretion and reduces sodium appetite. Nephropathy may be one of the main consequences of lead poisoning and its clinical features could be further deteriorated by these central actions of the metal.

\section{Acknowledgments}

We are thankful to Mr. Vanilson Souza and Mr. José de Souza for their skilful technical assistance.

\section{References}

1. Boivin MJ \& Giordani B (1995). A risk evaluation of the neuropsychological effects of childhood lead neurotoxicity. Developmental Neuropsychology, 11: 157180.

2. Winneke $G$, Lillienthal $H \&$ Kramer $U$ (1996). The neurobehavioral toxicology and teratology of lead. Archives of Toxicology, 18 (Suppl): 57-70.

3. Ferguson SA, Holson RR, Gazzara RA \& Siitonen PH (1998). Minimal behavioral effects from moderate postnatal lead treatment in rats. Neurotoxicology and Teratology, 20: 637-643.

4. Al-Saleh IAS (1994). The biochemical and clinical consequences of lead poisoning. Medicinal Research Reviews, 14: 415486.

5. Bellinger DC (1995). Interpreting the literature on lead and child development: The neglected role of the "experimental system". Neurotoxicology and Teratolo- gy, 17: 249-251.

6. Fregoneze JB, Cunha $M$, Bulcão $C$, Ferreira H \& De Castro e Silva E (1994). Acute effect of intracerebroventricular administration of lead on the drinking behavior of rats induced by dehydration or central cholinergic and angiotensinergic stimulation. Physiology and Behavior, 56: 129133.

7. Fregoneze JB, Marinho CA, Soares $T$, Castro L, Sarmento C, Cunha M, Gonzalez 
V, Oliveira $P$, Nascimento $T$, Luz CP, Santana J r P, De-Oliveira IR \& De-Castroe-Silva E (1997). Lead $\left(\mathrm{Pb}^{2+}\right)$ and cadmium $\left(\mathrm{Cd}^{2+}\right)$ inhibit the dipsogenic action of central beta-adrenergic stimulation by isoproterenol. Brazilian J ournal of Medical and Biological Research, 30: 419-423.

8. De-Castro-e-Silva E, Luz CP, Sarmento C, Nascimento T, Gonzalez V, Marinho CA, Castro L, Oliveira P, Santana J r P, DeOliveira IR, De-Paula S, Lima AKS \& Fregoneze J B (1998). Opiatergic participation in the thirst-inhibiting effect of acute third ventricle injections of cadmium $\left(\mathrm{Cd}^{2+}\right)$ and lead $\left(\mathrm{Pb}^{2+}\right)$. Brazilian J ournal of Medical and Biological Research, 31: 805-810.
9. Fregoneze J B, Luz CP, Sarmento C, Gonzalez V, Oliveira P, Santana J r P, Marinho CA, Castro L, Nascimento T, De Paula S, Lima AKS, De-Oliveira IR \& DeCastro e Silva E (1998). Central lead administration induces natriuretic and kaliuretic effects in rats. Physiology and Behavior, 65: 321-326.

10. Antunes-Rodrigues J \& McCann SM (1970). Water, sodium and food intake induced by injections of cholinergic and adrenergic drugs into the third ventricle of rat brain. Proceedings of the Society for Experimental Biology and Medicine, 133: 1464-1470.

11. Goldstein GW (1994). Brain capillaries: A target for inorganic lead poisoning. Neu- rotoxicology, 5: 167-176.

12. Goldstein GW (1990). Lead poisoning and brain cell function. Environmental Health Perspectives, 89: 91-94.

13. J ohnson AK \& Thunhorst RL (1997). The neuroendocrinology of thirst and salt appetite: Visceral sensory signals and mechanisms of central integration. Frontiers in Neuroendocrinology, 18: 292-353.

14. Fitzsimons J T (1998). Angiotensin, thirst, and sodium appetite. Physiological Reviews, 78: 583-686.

15. P'an AYS \& Kennedy C (1989). Lead distribution in rats repeatedly treated with low doses of lead acetate. Environmental Research, 48: 238-247. 